\title{
An Assessment of Available Models for the Design of Schottky-Based Multipliers Up to THz Frequencies
}

\author{
Diego Pardo, Jesús Grajal, Carlos G. Pérez-Moreno, and Susana Pérez
}

\begin{abstract}
This paper evaluates the ranges of application and physical limitations of lumped equivalent circuits and drift-diffusion models for the design of $\mathrm{THz}$ circuits. The predictions of these models have been compared with a Monte Carlo model, which was considered as a reference, and with measurements from doublers and triplers designed and fabricated by the Jet Propulsion Laboratory. Additionally, the usefulness of Schottky diodes as frequency multipliers above $3 \mathrm{THz}$ is analyzed with the Monte Carlo model.
\end{abstract}

Index Terms-Drift-diffusion (DD), frequency multiplier, lumped equivalent circuit, modeling, Monte Carlo (MC), Schottky diode, THz frequencies.

\section{INTRODUCTION}

$\mathbf{G}$ aAs Schottky barrier diodes are presently one of the most used solid-state devices for terahertz $(\mathrm{THz})$ applications [1]-[5]. Because of their high efficiency in frequency multipliers capable of reaching into the $\mathrm{THz}$ region, Schottky diodes are the technology most often used for building compact and robust local oscillators for heterodyne receivers [6]-[12]. On the other hand, Schottky mixers have the advantage over other sensor technologies to work at room temperature with excellent noise performance [5], [13]-[17]. Planar GaAs Schottky-diode frequency multipliers and mixers operating at frequencies up to $3 \mathrm{THz}$ have been designed and fabricated [11]-[13], [17].

Design and optimization of circuits based on Schottky diodes for high-frequency applications require reliable and accurate predictions of the device performance. The literature provides models with increasing accuracy and complexity, like lumped element equivalent circuit (LEC) [18]-[22], drift-diffusion (DD) [23]-[25], hydrodynamic (HD) [24], [26]-[28], and Monte Carlo (MC) [24], [29]-[33].

Successful results have been obtained by different research groups in the design and fabrication of Schottky based millimeter and submillimeter circuits by employing LEC models

Manuscript received July 16, 2013; revised September 20, 2013; accepted January 22, 2014. Date of publication February 19, 2014; date of current version March 04, 2014. This work was supported by the European Commission under Projects RooTHz (ICT-2009-243845) and MIDAS (FP7-SPACE-2009-1 242334), the Spanish National Research and Development Program under Projects TEC2010-15413 and TEC2011-28683-C02-01, TeraSense (Consolider- Ingenio 2010, CDS2008-00068) and the Junta de Castilla y Leon under Project SA052U13

D. Pardo, J. Grajal, and C. G. Pérez-Moreno are with the Signal, System and Radiocommunications Department, Technical University of Madrid, 28040 Madrid, Spain (e-mail: dpardo@gmr.ssr.upm.es, jesus@gmr.ssr.upm.es; carlos@gmr.ssr.upm.es).

S. Pérez is with the Applied Physics Department, University of Salamanca, 37008 Salamanca, Spain, (e-mail: susana@usal.es).

Color versions of one or more of the figures in this paper are available online at $\mathrm{http}: / /$ ieeexplore.ieee.org.

Digital Object Identifier 10.1109/TTHZ.2014.2304140
[2], [4], [5], [12], [15], [34]. These models are used because of their simplicity and ease of use in CAD tools [4], [12], [19]-[22]. However, LEC models are expected to fail at millimeter and submillimeter wavelength and/or high power levels, where physical processes in the device like velocity saturation, carrier inertia, displacement current in undepleted regions of the diode, plasma oscillations, or the nonstationary dynamics of the carriers begin to dominate the device operation [19], [20], [22], [25], [32], [33], [35]-[40]. Therefore, the validity of LEC models for the design of millimeter and submillimeter circuits has to be evaluated.

The aim of this paper is to analyze the range of validity of LEC and DD models in the design of frequency multipliers up to $\mathrm{THz}$ bands. The MC model has been selected as a reference. Doublers and triplers have been analyzed through the coupling of the different diode models to a harmonic-balance-based circuit simulator [25], [33], [41]. The performance of frequency multipliers above $3 \mathrm{THz}$ has been also explored taking into account the most significant limiting transport phenomena.

This paper is organized as follows. A brief review of available models to simulate Schottky diodes is presented in Section II. Section III compares measured data from frequency multipliers designed by the Jet Propulsion Laboratory with simulated results with different diode models. An analysis of the potential of Schottky diodes above $3 \mathrm{THz}$ is carried out in Section IV. The main conclusions are drawn in Section V.

\section{MOdeling SchotTKy DiOdeS}

Here, we present an overview of different models available in the literature for Schottky diodes. We are especially interested in modeling the charge transport close to the Schottky contact that is essentially one-dimensional (1-D) [Fig. 1(a)].

In the design of Schottky-based nonlinear circuits, the simple LEC of the Schottky junction in series with a constant resistance $R_{s}$ is commonly used; see Fig. 1(b). The nonlinear capacitance $C_{j}(V)$ is usually modeled with a fully depleted approximation. The conduction current through the Schottky contact is approached by thermionic emission equation [42]. The dc series resistance of the diode $R_{s, d c}$ (the series resistance measured when the epilayer is undepleted) is a good estimate for $R_{s}$ in LEC model of Fig. 1(b) at low frequencies [4], [5], [7]. In [18], a constant series resistance different from the dc series resistance is assumed to account for power losses in the device under time-dependent conditions. However, due to the time variation of the width of the depletion region, the series resistance is time varying $\left(R_{s}(\mathrm{t})\right)$ [18], [39], [43].

As the frequency of operation increases, the value of $R_{s}$ used in the simulations is increased to account for phenomena-like 


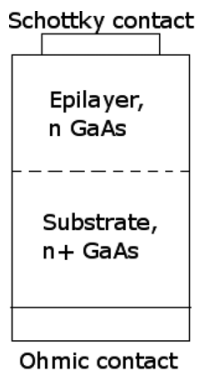

(a)

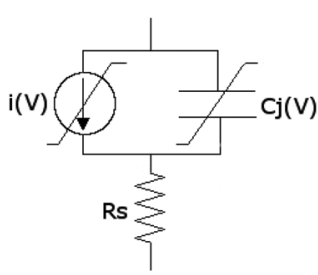

(b)

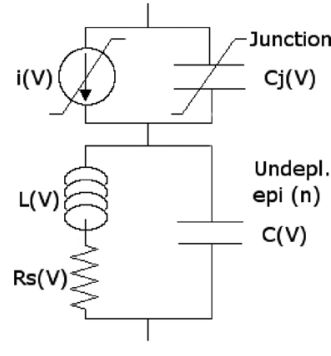

(c)
Fig. 1. (a) One-dimensional geometry of Schottky diode and equivalent circuit models of the epilayer: (b) simplified and (c) extended.

velocity saturation [4], [5], [36]. This phenomenon can be indirectly included in the diode model by fixing the product $R_{s} \times$ $C_{j}(0)$ to values that depend on the output frequency and the operation temperature [21]. A $R_{s} \times C_{j}(0)$ product of $120 \Omega$. $\mathrm{fF}$ at $300 \mathrm{~K}$ is used for output frequencies between 1.3 and $2.7 \mathrm{THz}$ (different values must be considered at different frequency ranges). The $R_{s} \times C_{j}(0)$ rule was determined regardless of diode doping. However, a doping of $1 \times 10^{17} \mathrm{~cm}^{-3}$ was considered in the development of this rule, according to [4]. This rule has been successfully applied in the design of a tripler at 540-640 GHz [4], [7], but only some publications have clearly declared the use of this rule [7], [44], [45].

LEC models can be updated to account for charge carrier inertia, which becomes important at frequencies of the order of $1 \mathrm{THz}$, and the displacement current in the undepleted regions of the device, which have been included in the model through an inductance (L) and a capacitance (C), respectively [19], [20], [22], [40]; see Fig. 1(c).

The validity of the approximations considered in LEC models is questionable at millimeter and submillimeter wavelengths because of the large-signal nonstationary high-frequency dynamics of carrier transport [5], [25], [31]-[33], [37], [39].

In physics-based models, carrier transport is commonly described by the semiclassical Boltzmann transport equation (BTE). However, finding the exact solution to the BTE is a very difficult task, so different approaches are generally employed [24]. Fig. 2 shows a rough estimation of the valid operation ranges for different available approaches of the BTE.

Physics-based drift-diffusion model [23], [24] for Schottky diodes, based on the first two moments of the BTE and the Poisson's equation, assumes that transport parameters such as mobility and diffusion coefficients are determined by local values of the electric field. The velocity saturation, which becomes a limiting effect of the diode performance at input frequencies above $100 \mathrm{GHz}$ [36], is taken into account in the DD model by means of a field-dependent mobility. However, it does not take into account nonstationary characteristics such as carrier heating and velocity overshoot [24], [38], [46]. These effects are important in the performance of GaAs nanometric diodes operating at submillimeter wavelengths [24], [28].

Other approaches derived from BTE are the hydrodynamic and energy transport models, which are obtained by taking the first three moments of the BTE (conservation of particles, momentum, and energy) [24], [26]-[28], [46]. The effects of scattering are described by macroscopic relaxation times [24], [28].

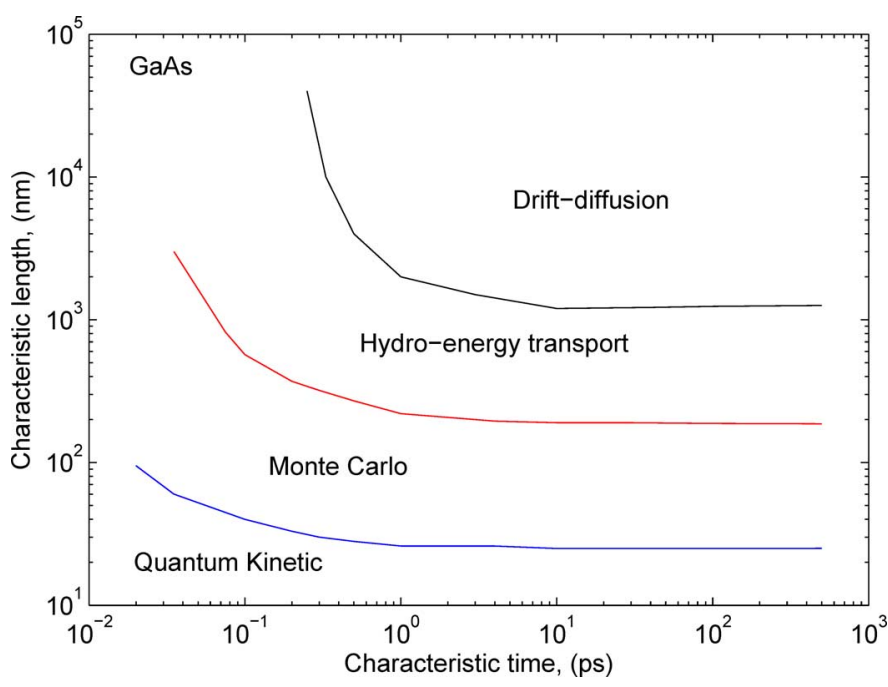

Fig. 2. Illustration of the regions of validity of the physics-based semiconductor models, from [24].

TABLE I

SumMARY OF Described SCHOTTKY Diode Models

\begin{tabular}{|c|c|c|c|c|}
\hline \multirow{2}{*}{ Physical phenomena } & \multicolumn{4}{|c|}{ Model } \\
\cline { 2 - 5 } & LEC & DD & HD & MC \\
\hline Carrier inertia & No $^{\text {a }}$ & No & Yes & Yes \\
\hline Displacement current in undepleted regions & No $^{\text {a }}$ & Yes & Yes & Yes \\
\hline Velocity saturation & No & Yes & Yes & Yes \\
\hline Nonstationary effects & No & No $^{\text {b }}$ & Yes & Yes \\
\hline Nonlocal effects & No & No & Yes & Yes \\
\hline$\mu_{0}$ dependent on epilayer length & No & No & No & Yes \\
\hline
\end{tabular}

a It can be modeled by an inductance (inertia) or a capacitance (displacement current).

${ }^{b}$ Nonstationary effects can be modeled by employing weighted average ac mobility models [33], [38].

In addition to velocity saturation, these approximations model nonstationary effects due to energy and momentum relaxation, which are important at frequencies of the order of the inverse of the energy and momentum relaxation times, above $300 \mathrm{GHz}$ and $1 \mathrm{THz}$, respectively [24], [28].

The MC method is based on the microscopic modeling of the interactions of the charge carriers with the crystal lattice (scattering mechanism) and the external fields [29]. Therefore, this technique provides an accurate description of physical phenomena in the device up to $\mathrm{THz}$ frequencies. The ensemble $\mathrm{MC}$ self-consistently coupled with a 1-D Poisson solver used in this paper is described in [30]. The ohmic contact is modeled as a surface that injects carriers in thermal equilibrium with the lattice. In addition, any carrier reaching the contact leaves the device. On the other hand, the Schottky contact is simulated as a perfect absorbent surface. Scattering mechanisms included in the MC simulation are ionized impurities, acoustic phonon, polar and nonpolar optic phonon, and intervalley mechanisms. The band structure is modeled as a conduction band with three spherical nonparabolic valleys [47]. The charge density is updated every $0.5-1$ fs and the device is divided into equal cells of $20 \AA$ long.

Table I shows a summary of the diode models presented and the physical effects that they take into account. 
TABLE II

Schottky Diode Structures USEd in JPL Multipliers AND DATA CONSIDERED In OUR Simulations

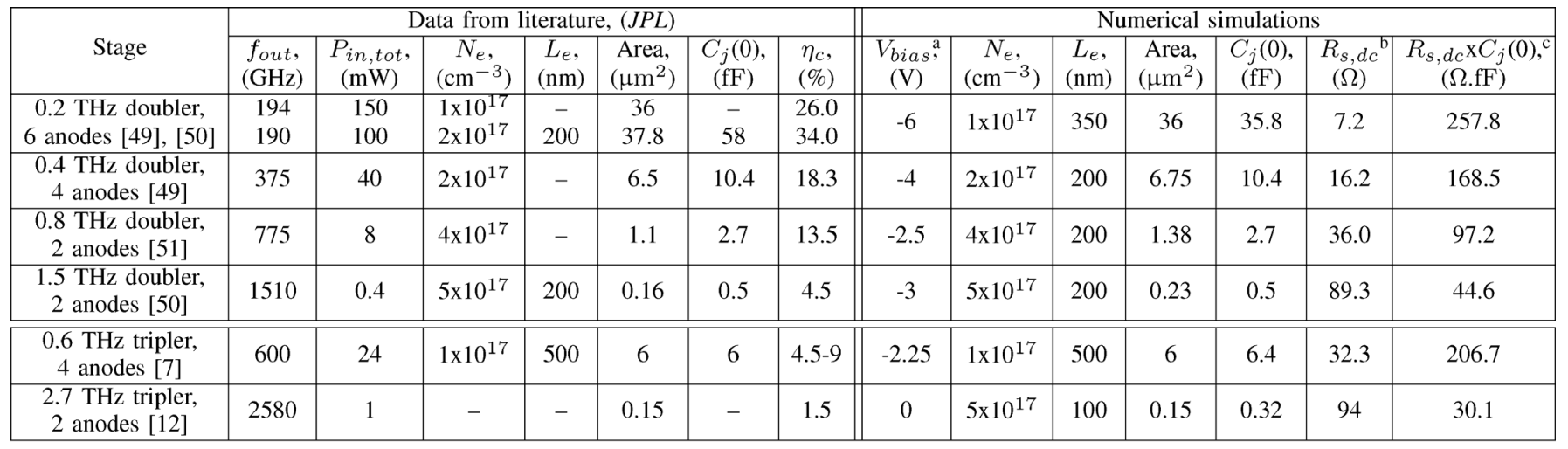

${ }^{\text {a }}$ Bias point is not provided in the literature. It has been optimized to obtain maximum efficiency.

${ }^{\mathrm{b}}$ Calculated with the DD model under dc conditions (MC predicts similar $R_{s, d c}$ ).

${ }^{c}$ Obtained with $R_{s, d c}$ and $C_{j}(0)$ from DD simulations under de conditions.

${ }^{\mathrm{d}}$ An ideal barrier height of $\phi_{b}=0.99 \mathrm{~V}$ is assumed except for the $0.6 \mathrm{THz}$ tripler where $\phi_{b}=0.85 \mathrm{~V}$ [7]

MC, DD, and LEC diode models have been coupled to a harmonic-balance circuit analysis technique [25] (denoted by MCHB, DDHB, and LECHB, respectively) to analyze the performance of multiplier circuits. Since the MC technique provides the most accurate description of the electron dynamics at high frequencies and high electric fields, the predictions of the MCHB are considered as a reference. A DD model that imposes a constant low-field mobility independently of the electric field (denoted by $\mathrm{DD}_{0}$ model) will be also considered. $\mathrm{DD}_{0} \mathrm{HB}$ will provide the upper limit of the circuit efficiency since it neglects velocity saturation. LEC models based on a constant series resistance (denoted by $\mathrm{LEC}_{R_{s}} \mathrm{HB}$ ) and a time varying resistance $\left(\mathrm{LEC}_{R_{s}(t)} \mathrm{HB}\right)$ due to time-varying space charge region are considered. Among the first ones, LEC models based on the dc series resistance $\left(\mathrm{LEC}_{R_{s, d c}} \mathrm{HB}\right)$ and $R_{s}$ from the $R_{s} \times$ $C_{j}(0)$ rule $\left(\mathrm{LEC}_{R_{s, R_{s} \times C_{j}(0)}} \mathrm{HB}\right)$ are used in the following sections. The models used in this paper take into account neither self-heating nor skin effect. It is well known that the importance of skin effect increases with frequency [19], [48]. However, this is a linear effect that can be included in the linear part of the circuit, not necessarily as part of these nonlinear models. In addition, there are limiting effects in the performance of Schottky diodes like velocity saturation [36] and plasma effects that are more important than skin effect [48].

\section{Frequency Multipliers Performance Evaluated WiTH DiFFERENT MODELS}

Here, we present a comparison between measurements of multipliers designed and fabricated by JPL in the frequency range $200-2700 \mathrm{GHz}$ and simulation results obtained with different diode models.

The data of the JPL multipliers analyzed in this section are compiled in Table II. The values of the epilayer doping, zerovoltage junction capacitance, and available input power provided in the literature for JPL circuits are employed in the simulations; see Table II. However, because of the lack of information, unknown characteristics like the epilayer length and bias voltage have been optimized to obtain the maximum efficiency [52]. In some cases, the anode areas employed in the numerical simulations have been slightly modified with respect to the nominal values provided in the literature so that the measured and simulated capacitance coincide. To determine the characteristics of the substrate of the diodes used in the simulations, measurements of the series resistance $R_{s, d c}$ (see Section II) are required. However, due to the lack of this information, the substrate of the diodes were selected to obtain efficiencies with MCHB similar to measurements at the available input power, leading to the $R_{s, d c}$ shown in Table II (substrate doping of $2 \times 10^{18} \mathrm{~cm}^{-3}$ has been assumed in simulations). These values of $R_{s, d c}$ are close to those presented by JPL in [53].

In the design of the multipliers presented in Table II, JPL uses an LEC to model the nonlinear Schottky diode and a 3-D electromagnetic field solver to take into account the 3-D topology of the full diode structure [4], [7], [21], [40]. This modeling technique has led to good results compared with measurements up to THz frequencies [7], [10], [12], [49]-[51]. The $R_{s} \times C_{j}(0)$ rule [21] has been used in some of these designs [7], so the last column of Table II presents such a magnitude for the diodes considered, calculated with $R_{s, d c}$ and $C_{j}(0)$ from dc simulations.

In the circuital simulations, diodes are always matched at the fundamental frequency. On the other hand, the load impedance at the output frequency is optimized for maximum conversion efficiency at the available input power. However, in real circuits, coupling the input power to the diodes and the output power to the circuit presents limitations [7], [10], [54]. Thus, to account for these losses in our simulations, the efficiencies predicted for the diodes $\eta_{d}$ must be modified by the coupling efficiencies of the input and output circuits to obtain the flange-to-flange efficiency of the circuit $\eta_{c}$ [55], [56] as

$$
\eta_{c}=\frac{P_{\text {out }}}{P_{\text {in }}}=\frac{\beta P_{d, \text { out }}}{\frac{P_{d, \text { in }}}{\alpha}}=\alpha \beta \frac{P_{d, \text { out }}}{P_{d, \text { in }}}=\alpha \beta \eta_{d}
$$

where $P_{\text {in }}$ is the input power delivered to the circuit, $P_{\text {out }}$ is the output power delivered to the external load, $P_{d, \text { in }}$ is the input power delivered to the diodes, $P_{d, \text { out }}$ is the output power delivered by the diodes to the output, $\alpha$ represents the coupling factor of the input power, and $\beta$ is the coupling factor of the output power. $\alpha=0.8$ and $\beta=0.875(\alpha \beta=0.7)$ have been 


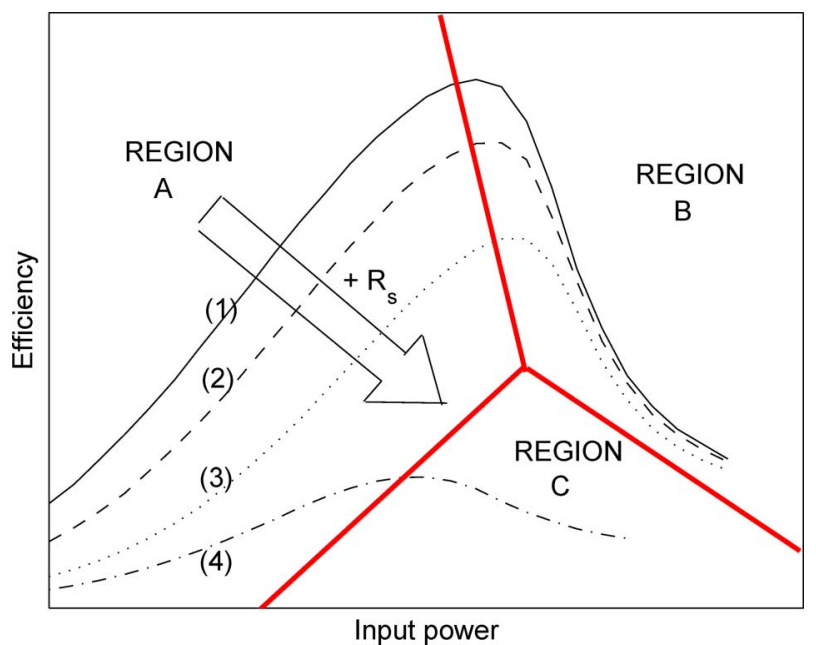

Fig. 3. Efficiency of frequency multipliers. Regions of operation. The series resistance of curves (1) to (4) evaluated in region A are 3, 4, 6, and $8 \Omega$, respectively.

assumed to relate $\eta_{c}$ and $\eta_{d}$ for the multipliers in this section. These values are in accordance with published data [7], [10], [55].

Fig. 3 presents a schematic efficiency-versus-power diagram for frequency multipliers. Three different regimes of operation can be identified. Region A represents a low-power regime, where circuit performance is dominated by the series resistance. In Region B, the efficiency is limited by forward or reverse conduction if this regime is reached. In region $C$, velocity saturation limits the efficiency of the multipliers before entering the conduction regime. The arrow in the figure means that, if the device geometry and doping change and these changes produce an increase in the series resistance of the diode, there is a decrease in the efficiency.

\section{A. Comparison Between Measurements and Simulations}

Fig. 4 shows the flange-to-flange efficiency for fabricated doublers and triplers [7], [10], [12], [49]-[51], [57] (Table II) and simulated results with different diode models. These efficiencies have been evaluated at the input power delivered to the circuit indicated in the third column of Table II. A detailed analysis with the input power is carried out in Figs. 5-7. According to the discussion about coupling efficiency, a factor $\alpha \beta \sim 0.7$ [see (1)] has been assumed to calculate the circuit efficiency from the simulated diode efficiency.

An empirical relation published in [58] for the efficiency of doublers as a function of the output frequency has been included in Fig. 4. This relation obtained by fitting measured flange-toflange efficiencies of planar JPL doublers is of the form $\eta(f)=$ $\eta_{0} \exp \left(-f / f_{0}\right)$ (at $295 \mathrm{~K}, \eta_{0}=0.45$ and $f_{0}=600 \mathrm{GHz}$ ).

Since Monte Carlo provides the most accurate simulation of the physical phenomena in the diode, MCHB is considered as a reference to evaluate the limitations of simpler models. $\mathrm{DD}_{0} \mathrm{HB}$ shows a good agreement with $\mathrm{MCHB}$ until velocity saturation is relevant in the performance of the diode, as happens in the $1500-\mathrm{GHz}$ doubler and the $2.7-\mathrm{THz}$ tripler; see Fig. 4. The LEC model based on the dc series resistance $R_{s, d c}$ produces reasonable results for doublers and the $600-\mathrm{GHz}$ tripler.

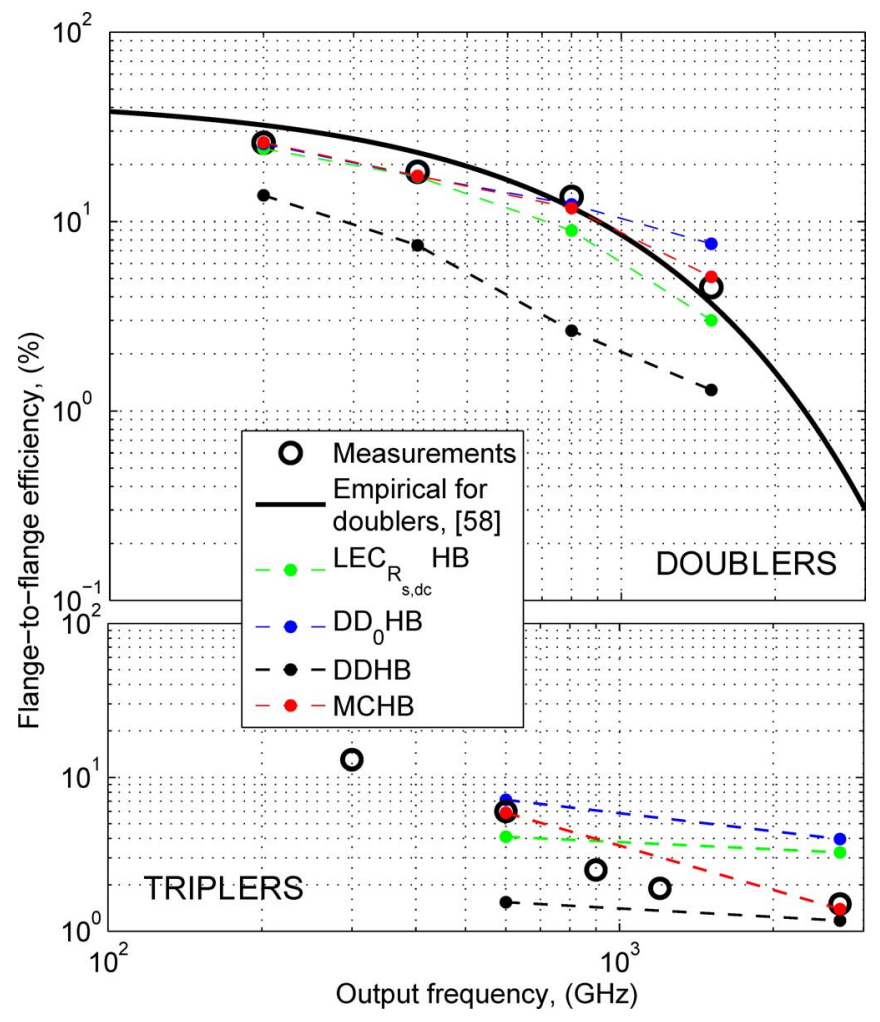

Fig. 4. Efficiency of the doublers and triplers [7], [10], [12], [49]-[51], [57] in Table II as a function of the output frequency, evaluated at the input power delivered to the circuit (the third column of Table II). A factor $\alpha \beta \sim 0.7$ has been assumed to account for coupling losses and transform the simulated diode efficiencies to circuit efficiencies or flange-to-flange efficiencies.

Section III-B shows the limitations of the LEC model and the modifications that improve its performance: a time-varying resistance $R_{s}(\mathrm{t})$ and the degradation of the nonlinear capacitance when the depletion region reaches the substrate. These simple improvements make LEC performance very similar to $\mathrm{DD}_{0}$ performance. However, none of them takes into account velocity saturation. This phenomenon can be included in the LEC model by setting an adequate series resistance in the model (e.g., the $R_{s}$ provided by the $R_{s} \times C_{j}(0)$ rule).

On the other hand, although DD models velocity saturation, it overestimates the contribution to the series resistance of the diode from the region close to the depletion region since this model evaluates locally the electron mobility; see Appendix A. Therefore, DDHB underestimates the efficiency of the multipliers. Only when velocity saturation is the dominant limiting effect as occurs in the $2.7-\mathrm{THz}$ tripler, DDHB predicts the measured efficiency results.

Regarding the impact of avalanche breakdown in the performance of the analysed structures, we have tested through the DD model that is not a limiting mechanism for these multipliers.

A detailed analysis of the selected multipliers with different models is presented in the following subsections.

\section{B. Doublers Up to $1.5 \mathrm{THz}$}

Fig. 5 shows the diode efficiency obtained from simulations of $J P L$ doublers described in Table II [49]-[51], [59], as a function of the input power delivered to the diode $P_{d, i n}(1)$. The most 


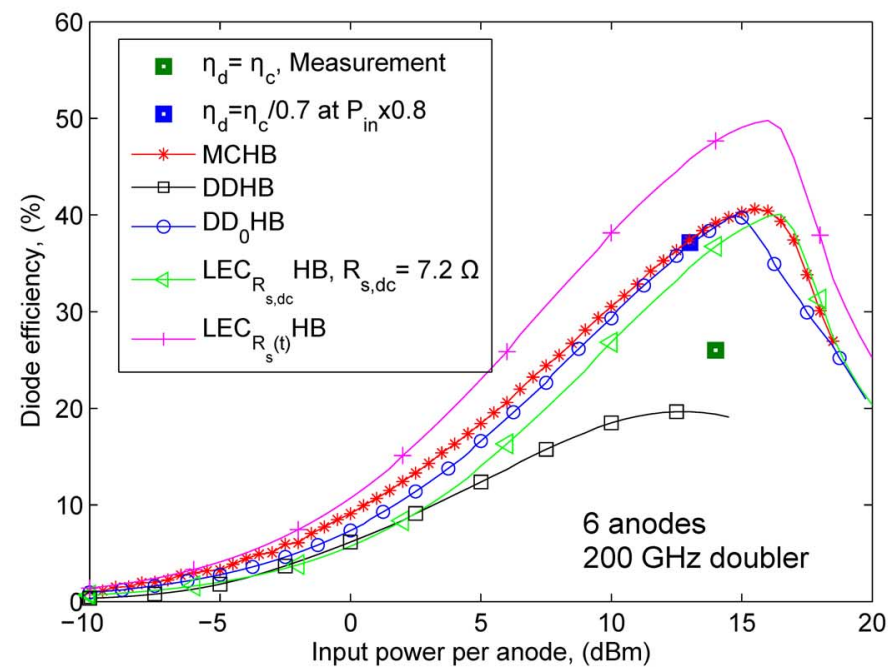

(a)

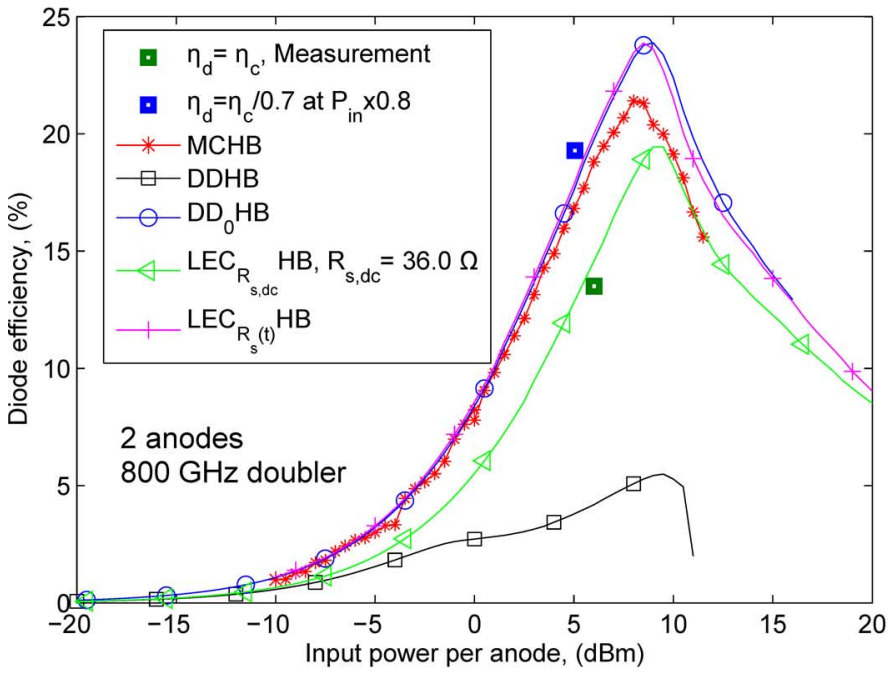

(c)

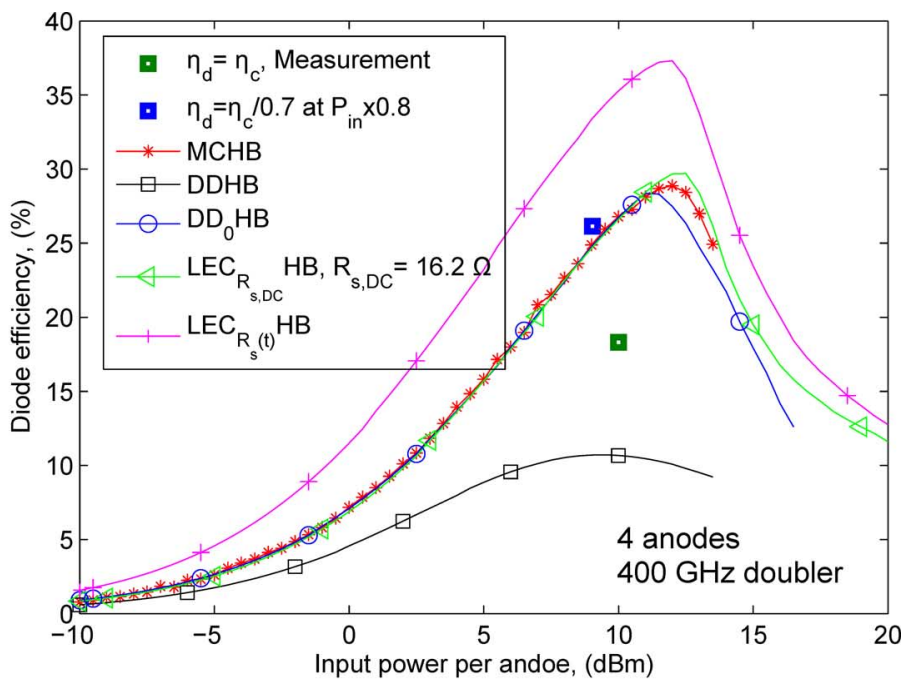

(b)

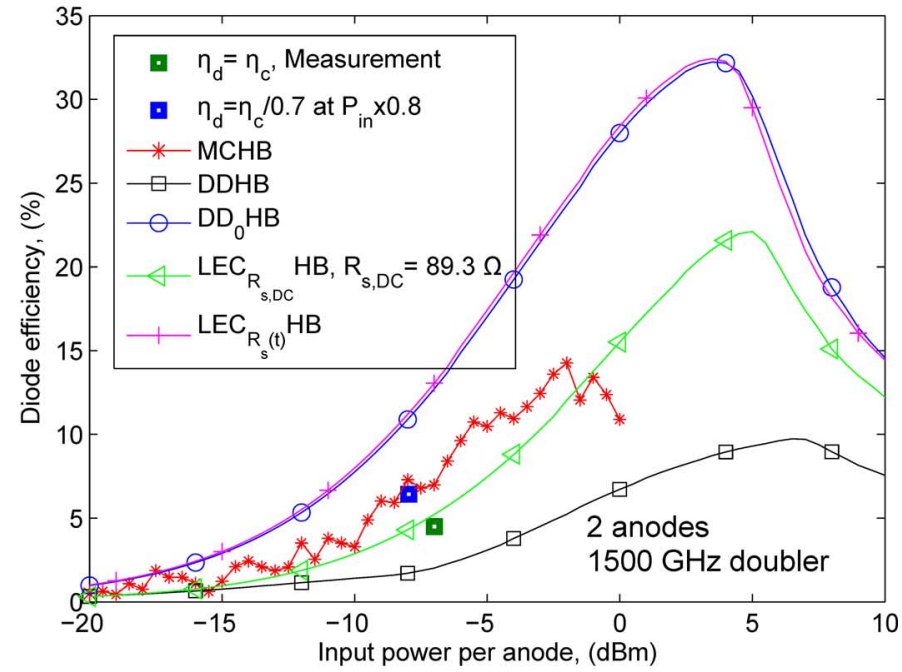

(d)

Fig. 5. Diode efficiency of doublers described in Table II [49]-[51], [59] as a function of the input power delivered to the diode $P_{d, \text { in }}$ (1), simulated with LECHB, $\mathrm{DD}_{0} \mathrm{HB}, \mathrm{DDHB}$ and MCHB tools.

relevant results from the analysis of Fig. 5 are summarized in the following items:

1) For the 200- and $400-\mathrm{GHz}$ doublers, a good agreement is observed between $\mathrm{MCHB}$ and $\mathrm{DD}_{0} \mathrm{HB}$ since there is no velocity saturation and $\mathrm{DD}_{0} \mathrm{HB}$ does not overestimate the series resistance of the diodes. Physics-based models show that the depletion region of these doublers reaches the substrate, so, the predictions of LECHB are not reliable, since they are based on the simple Schottky junction model [Fig. 1(b)]. A more sophisticated LEC model that takes into account the time variation of the series resistance $R_{s}(t)$ and the degradation of the nonlinear capacitance when the depletion region reaches de substrate will work correctly until velocity saturation becomes important. In fact, for the 800-GHz doubler, where the depletion region does not reach the substrate, $\mathrm{LEC}_{R_{s}(t)} \mathrm{HB}$ shows a good agreement with MCHB at input powers up to $5 \mathrm{dBm}$.

2) For the $800-\mathrm{GHz}$ doubler with high power and the $1500-\mathrm{GHz}$ doubler, velocity saturation limits the efficiency of the devices (region $\mathrm{C}$ in Fig. 3), so, the efficiency from MCHB becomes lower than that from $\mathrm{DD}_{0} \mathrm{HB}$ simulations as the input power increases. A good agreement is observed between $\mathrm{DD}_{0} \mathrm{HB}$ and $\mathrm{LEC}_{R_{s}(t)} \mathrm{HB}$.

3) $\mathrm{DD}$ model overestimates the series resistance of the diodes due to the local evaluation of the electron mobility in the transition between the neutral and the depleted regions of the epilayer; see Appendix A. Therefore, according to the performance of region A in Fig. 3, DDHB presents a conservative approach for the efficiency compared with measurements and MCHB.

In Fig. 6, the $1500-\mathrm{GHz}$ doubler is analyzed with different LEC models. The performance of this doubler is limited by velocity saturation. Besides the models used in Fig. 5(d), a LEC model based on the constant average series resistance of the diode (denoted by $\mathrm{LEC}_{<R_{s}>} \mathrm{HB}$, where the average resistance has been evaluated from the simulations with $\left.\mathrm{LEC}_{R_{s}(t)} \mathrm{HB}\right)$ and the predictions of the $R_{s} \times C_{j}(0)$ rule are included. The efficiency obtained with $\mathrm{LEC}_{<R_{s}>} \mathrm{HB}$ is similar to that ob- 


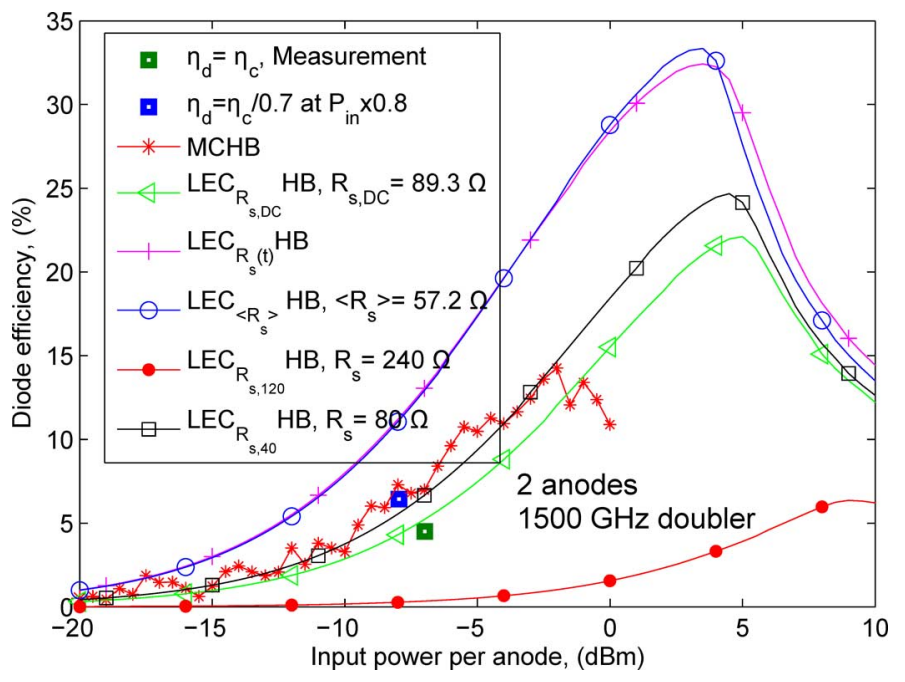

Fig. 6. Diode efficiency of the $1500-\mathrm{GHz}$ doubler described in Table II as a function of the input power delivered to the diode $P_{d, \text { in }}(1)$, simulated with MCHB and different LECHB.

tained assuming $R_{s}(t)$ in the LEC model. On the other hand, $R_{s} \times C_{j}(0)=120 \Omega \cdot \mathrm{fF}$ rule $\left(\mathrm{LEC}_{R_{s, 120}} \mathrm{HB}\right)$ leads to simulated efficiencies lower than measurements and lower than the predictions of MCHB. Fig. 6 shows that $R_{s} \times C_{j}(0)=40 \Omega \cdot \mathrm{fF}$ $\left(\mathrm{LEC}_{R_{s, 40}} \mathrm{HB}\right)$ is necessary to reproduce measured efficiencies. The $R_{s} \times C_{j}(0)$ rule was developed for doping $1 \times 10^{17} \mathrm{~cm}^{-3}$ and output frequencies lower than $3 \mathrm{THz}$ [4], [21] while the doping of the this doubler is $5 \times 10^{17} \mathrm{~cm}^{-3}$. The extension of the rule for higher doping and frequencies requires the knowledge of the performance of the diode at such conditions that can be provided by simulation tools like MC.

\section{Triplers Up to $2.7 \mathrm{THz}$}

Fig. 7 shows the diode efficiency obtained for the $600-\mathrm{GHz}$ and 2.7-THz triplers presented in [7], [12]; see Table II. Unlike the doublers analyzed in the previous subsections, a complete set of parameters is provided for the $600-\mathrm{GHz}$ tripler in [7].

Velocity saturation limits the efficiency of both $600 \mathrm{GHz}$ and $2.7 \mathrm{THz}$ triplers and the performance of the simulation tools is similar to that described for the 800 and $1500 \mathrm{GHz}$ doublers. Unlike the $400-\mathrm{GHz}$ doubler, velocity saturation is important for the $600-\mathrm{GHz}$ tripler since its epilayer doping is only $1 \times 10^{17} \mathrm{~cm}^{-3}$, see Table II.

As was indicated for the doublers, DDHB underestimates the efficiency of the $600-\mathrm{GHz}$ tripler. However, a good agreement is observed between DDHB and MCHB simulators for the 2.7-THz tripler, since for this tripler the effect of velocity saturation is more important than the overestimation of the series resistance in DD simulations, see appendix A.

Neither $\mathrm{LEC}_{R_{s, d c}} \mathrm{HB}$ nor $\mathrm{LEC}_{R_{s}(t)} \mathrm{HB}$ lead to correct efficiency estimates for these triplers, since they do not model velocity saturation effects. For the $600-\mathrm{GHz}$ tripler, Erickson's rule [21] establishes $R_{s} \times C_{j}(0)=170 \Omega \cdot \mathrm{fF}$, that leads to a good agreement with measurements $\left(\mathrm{LEC}_{R_{s, 170}} \mathrm{HB}\right.$ in Fig. 7). However, in the design of this tripler, Maestrini et al. used $R_{s} \times$ $C_{j}(0)=120 \Omega \cdot \mathrm{fF}$. For the $2.7-\mathrm{THz}$ tripler, $R_{s} \times C_{j}(0)=$ $120 \Omega \cdot \mathrm{fF}$ is suggested by Erickson [21], but $R_{s} \times C_{j}(0)=$

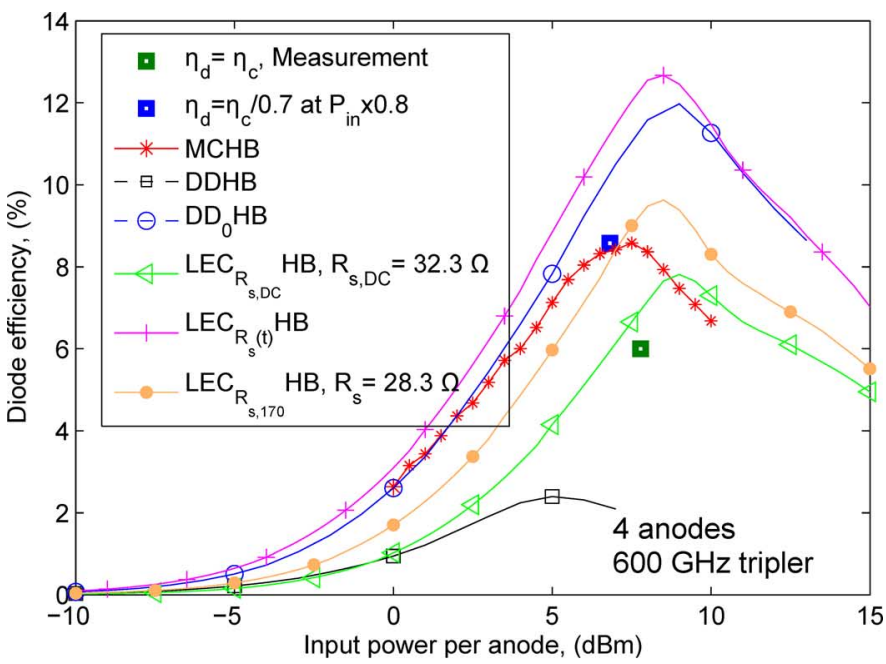

(a)

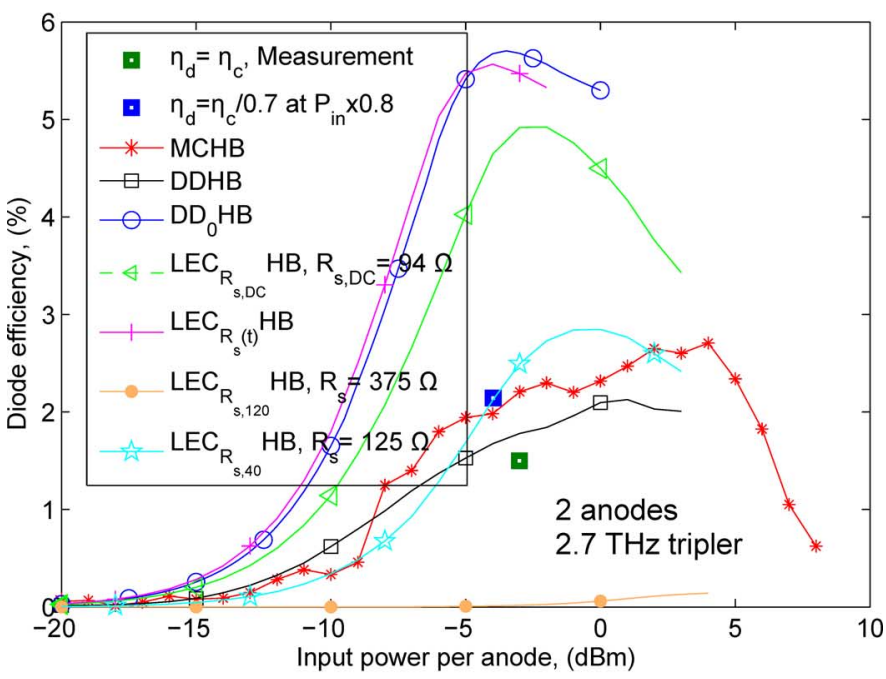

(b)

Fig. 7. Diode efficiency of the (a) $600-\mathrm{GHz}$ and (b) $2.7-\mathrm{THz}$ triplers presented in [7], [12], and Table II as a function of the input power delivered to the diode $P_{d, \text { in }}(1)$, simulated with LECHB, $\mathrm{DD}_{0} \mathrm{HB}$, DDHB, and MCHB tools.

$40 \Omega \cdot \mathrm{fF}$ is necessary to obtain efficiencies close to measurements (epilayer doping of the 2.7-THz tripler is $5 \times 10^{17} \mathrm{~cm}^{-3}$ ).

\section{Frequency Multipliers With Schottky Diodes ABOVE $3 \mathrm{THz}$}

Nowadays, Schottky-based multipliers have reached the 2.48-2.75-THz band, with a record output power for this technology of $18 \mu \mathrm{W}$ at $2.58 \mathrm{THz}$ at room temperature with an input power around $1 \mathrm{~mW}$ for the last stage tripler [12]. Table III shows a summary of published data on Schottky-based multipliers operating at frequencies above $1 \mathrm{THz}$. On the other hand, mixers at 5-6 THz based on Schottky diodes pumped with laser LO sources have been developed [69], [70]. This section presents an analysis of the performance of multiplier circuits at output frequencies above $3 \mathrm{THz}$.

Three fundamental phenomena must be considered for the accurate simulation of Schottky diodes at these frequencies:

1) Velocity saturation. 
TABLE III

Published Data on Schottky Based Multipliers at RoOm TEMPERATURE Operating AT OUtPUt Frequencies Higher Than 0.9 THz

\begin{tabular}{|c|c|c|c|c|c|c|c|c|c|c|}
\hline Circuit & $\begin{array}{c}\text { N. of } \\
\text { anodes }\end{array}$ & $\begin{array}{c}f_{\text {out }}, \\
(\mathrm{GHz})\end{array}$ & $\begin{array}{c}P_{\text {in }}, \\
(\mathrm{mW})\end{array}$ & $\begin{array}{c}P_{\text {out }}, \\
(\mu \mathrm{W})\end{array}$ & $\begin{array}{c}\eta_{c}, \\
(\%)\end{array}$ & $\begin{array}{c}N_{\text {epi }}, \\
\left(\mathrm{cm}^{-3}\right)\end{array}$ & $\begin{array}{c}L_{\text {epi }}, \\
(\mathrm{nm})\end{array}$ & $\begin{array}{c}\text { Area, } \\
\left(\mu \mathrm{m}^{2}\right)\end{array}$ & Year & Ref. \\
\hline $1.2 \mathrm{THz}$ tripler & 2 & 1130 & 8 & 70 & 0.9 & $5 \times 10^{17}$ & & 0.4 & 2001 & {$[49],[60],[61]$} \\
\hline $1.5 \mathrm{THz}$ doubler & 2 & 1522 & $5.2^{\mathrm{a}}$ & 55 & $\sim 1$ & $5 \times 10^{17}$ & 150 & & 2001 & {$[59],[62]$} \\
\hline $2.7 \mathrm{THz}$ tripler & 2 & 2550 & $6-7.5^{\mathrm{a}}$ & 0.1 & 0.002 & $5 \times 10^{17}$ & 100 & 0.76 & 2001 & {$[63],[64]$} \\
\hline $1.8 \mathrm{THz}$ tripler & 2 & 1810 & 5 & 1.5 & $\sim 0.03$ & $5 \times 10^{17}$ & & 0.32 & 2003 & {$[6],[45]$} \\
\hline $1.5 \mathrm{THz}$ doubler & 2 & 1500 & $\sim 0.4$ & $\sim 15$ & $\sim 4$ & $5 \times 10^{17}$ & 200 & 0.16 & 2004 & {$[50]$} \\
\hline $1.8 \mathrm{THz}$ tripler & 2 & 1740 & & 3 & 0.2 & $5 \times 10^{17}$ & & 0.32 & 2004 & {$[65]$} \\
\hline $1.8 \mathrm{THz}$ tripler & 2 & 1640 & & 21 & & $5 \times 10^{17}$ & & 0.4 & 2005 & {$[8]$} \\
\hline $0.9 \mathrm{THz}$ tripler & 4 & 857 & 48 & 1200 & 2.5 & $5 \times 10^{17}$ & & 1.2 & 2010 & {$[10]$} \\
\hline $1.8 \mathrm{THz}$ tripler & & 1900 & & 11 & & & & 0.5 & 2010 & {$[11],[66]$} \\
\hline $2.7 \mathrm{THz}$ tripler & 2 & 2580 & $\sim 1$ & $14-18$ & $\sim 1.5$ & & & 0.15 & 2011 & {$[12],[67],[68]$} \\
\hline $2.7 \mathrm{THz}$ tripler & & 2500 & & 3 & & & & & 2011 & {$[11]$} \\
\hline
\end{tabular}

${ }^{a}$ Laser pump source.

2) Plasma resonance of the epilayer and the substrate of the Schottky diode. This phenomenon leads to the fast increase of the real part of the diode impedance at input frequencies near to the plasma frequency. This phenomenon also affects to the imaginary part of the diode impedance, that becomes positive at frequencies close to the epilayer plasma frequency [20], [48], [71].

3) Nonstationary effects become important when the timescale of the applied signal is lower than the energy and/or the momentum relaxation times $\tau_{\epsilon}$ and $\tau_{m}$, respectively $\left(\tau_{\epsilon} \simeq 3 \mathrm{ps}\right.$ and $\tau_{m} \simeq 0.25 \mathrm{ps}$ for GaAs [28]).

For the doublers and triplers presented in this section, only MCHB gives reliable results because MC is the only model that takes into account correctly these phenomena.

As a reference in this section, one anode multipliers based on a Schottky diode like that described in Table II for the $2.7-\mathrm{THz}$ tripler are considered: epilayer doping $5 \times 10^{17} \mathrm{~cm}^{-3}$, epilayer length $100 \mathrm{~nm}$, and anode area $0.15 \mu \mathrm{m}^{2}$. The bias point selected for these simulations is $0 \mathrm{~V}$. The load impedances for the doublers and triplers presented in this section have been optimized at an input power of $0.5 \mathrm{~mW}$ per anode.

Fig. 8 presents the efficiency and the real part of the diode impedance for doublers at output frequencies above $3 \mathrm{THz}$ obtained with MCHB. Two phenomena are important in the performance of these multipliers: At low input powers, the real part of the impedance increases [Fig. 8(b)] as the input frequency increases, due to plasma effects (plasma frequency for doping $5 \times 10^{17} \mathrm{~cm}^{-3}$ is around $6.8 \mathrm{THz}$ [71]). When increasing the input power, the electrons gain enough energy from the field to scatter into the upper valleys and this produces velocity saturation [40], leading to the abrupt increase of the real part of the diode impedance observed in Fig. 8(b).

To mitigate both plasma resonance and saturation velocity effects, the epilayer doping $N_{e}$ can be increased; see Fig. 9 for the diode efficiency of the 6-THz doubler. However, increasing the doping causes the reduction of the efficiency due to the reduction of the modulation of the nonlinear capacitance. Therefore, a joint optimization of the epilayer doping and length is necessary. Analyzing the waveforms at the diode contacts, breakdown does not limit the performance of these multipliers.

Fig. 10 presents the diode efficiency for triplers based on the reference diode. The performance of the triplers is similar to that described for the doublers: Velocity saturation limits the performance. This phenomenon causes the abrupt increase of the real

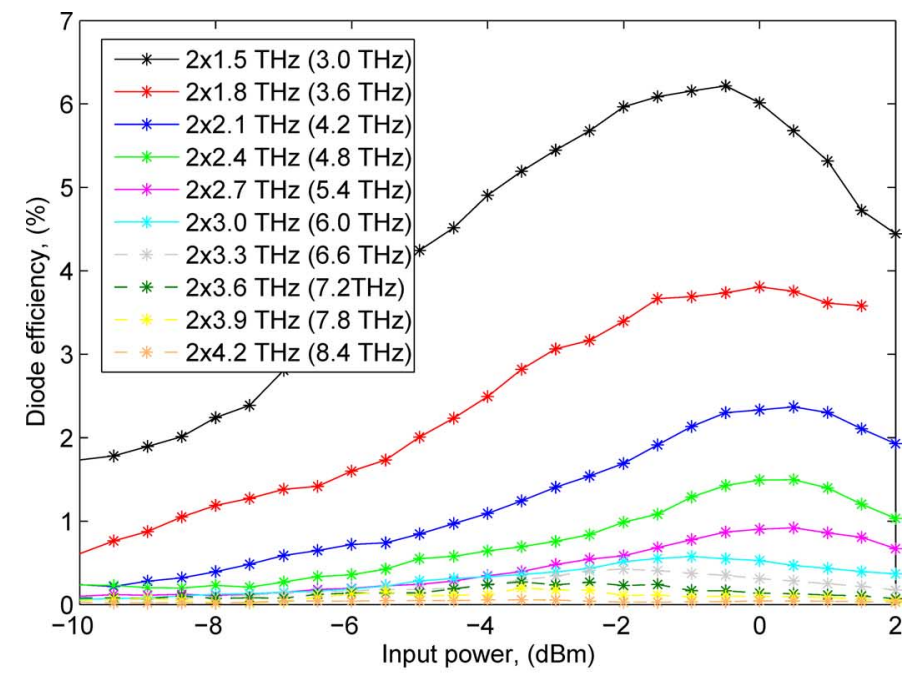

(a)

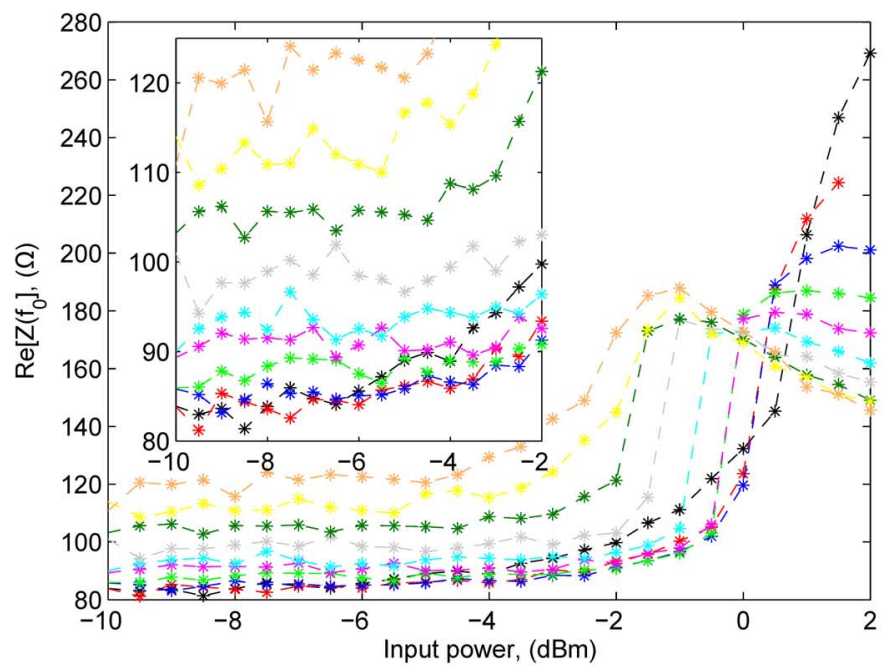

(b)

Fig. 8. (a) Diode efficiency and (b) real part of the diode impedance as a function of the input power delivered to the diode for doublers based on the reference diode at different input frequencies, obtained with MCHB. The anode area is fixed to $0.15 \mu \mathrm{m}^{2}$.

part of the diode impedance as was observed for doublers. Note that the efficiencies obtained for these triplers are close to that shown in Table III. 


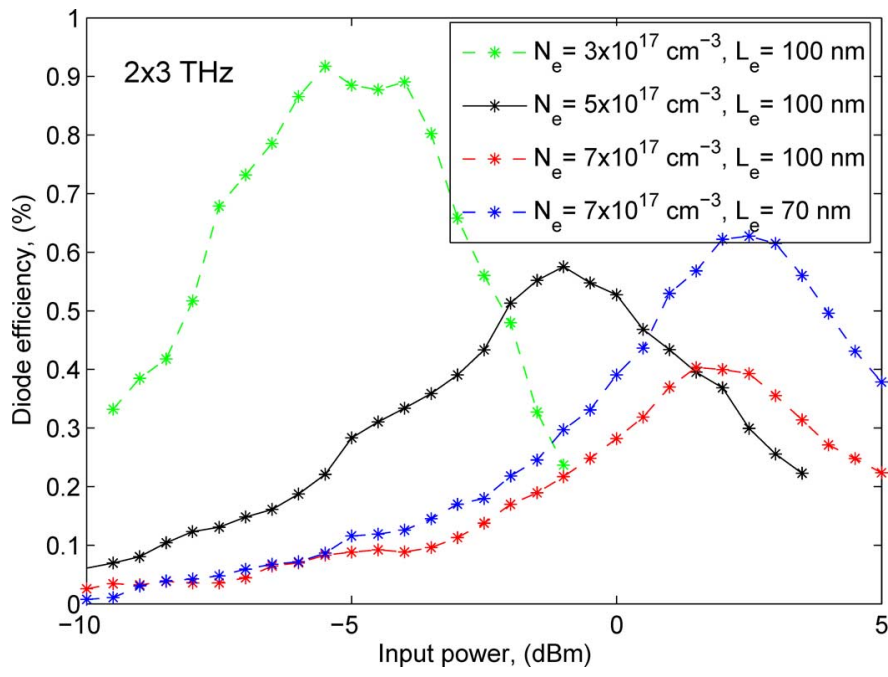

Fig. 9. Diode efficiency of 6-THz doublers for different epilayer doping of the reference diode as a function of the input power delivered to the diode, obtained with MCHB. The anode area is fixed to $0.15 \mu \mathrm{m}^{2}$.

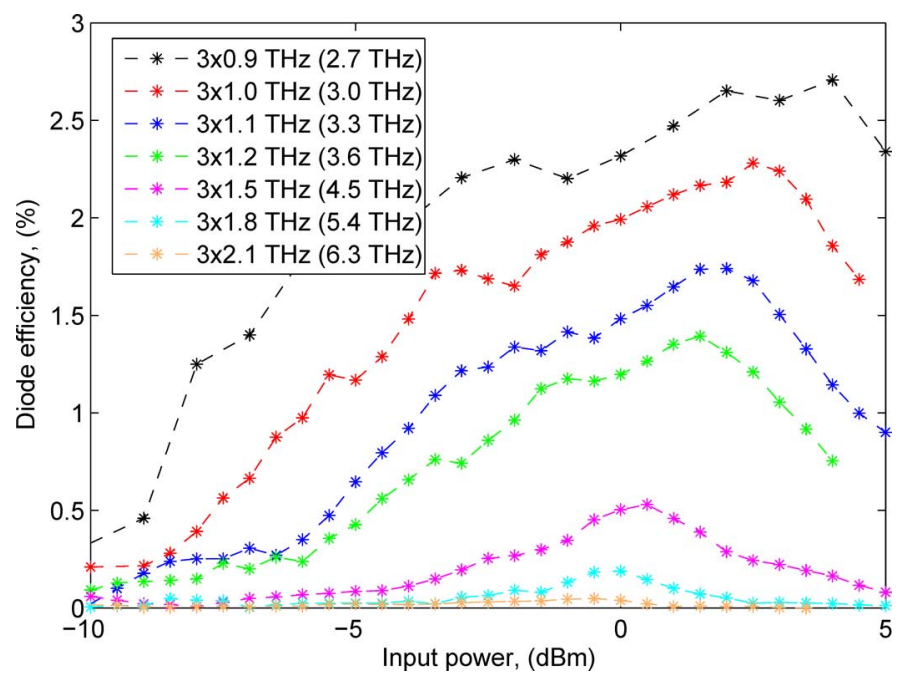

Fig. 10. Diode efficiency as a function of the input power delivered to the diode for triplers based on the reference diode at different input frequencies, obtained with MCHB. The anode area is fixed to $0.15 \mu \mathrm{m}^{2}$.

Fig. 11 presents the measured output power per anode for JPL doublers and triplers [7], [10], [12], [49]-[51], [57] (Table II) and simulation results for multipliers above $3 \mathrm{THz}$, Figs. 8 and 10. Regarding the experimental results, the output power has been evaluated at the available input power, which is close to the power for maximum efficiency-Figs. 5 and 7 - except for the $1.5-\mathrm{THz}$ doubler. The $1.5-\mathrm{THz}$ doubler is not an optimum design because its output power is similar to the power of the 2.7-THz tripler. For the simulated multipliers above $3 \mathrm{THz}$, the predicted output power has been calculated with the maximum efficiency in Figs. 8 and 10 for a fixed input power per anode of $-7 \mathrm{dBm}$, which is the available input power for the $1.5-\mathrm{THz}$ doubler. ${ }^{1}$

The experimental output power per anode is approximately proportional to $f^{-2}$ and $f^{-2.5}$ for doublers and triplers, respec-

\footnotetext{
${ }^{1}$ The maximum efficiency can be located at the desired input power by scaling the anode area [25].
}

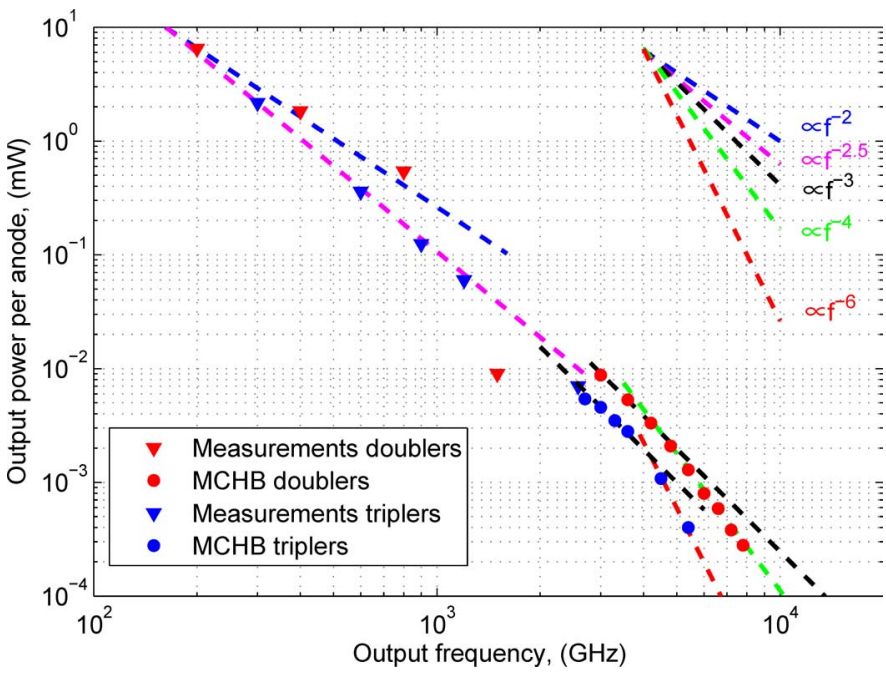

Fig. 11. Measured output power per anode for JPL doublers and triplers [7], [10], [12], [49]-[51], [57] (Table II) and simulation results for the multipliers above 3 THz (Figs. 8 and 10) at room temperature.

tively. When the performance is limited by velocity saturation (doublers above 800 and triplers above $600 \mathrm{GHz}$ according to the discussion in Section III), the output power is proportional to $f^{-3}$. The output power drops at higher rates when the electron transport is dominated by nonstationary phenomena in the momentum and energy [35], [38].

According to Monte Carlo simulations, doublers and triplers based on GaAs Schottky diodes are expected to operate up to 6 and $4 \mathrm{THz}$, respectively, with efficiency higher than $0.5 \%$.

\section{CONCLUSION}

The analysis of submmillimeter-wave Schottky multipliers has been carried out with different diode models. The only model that includes all of the important physical phenomena is Monte Carlo, which can be considered as a practical tool for the analysis and design of Schottky-based circuits due to improvements in computer technology. Simpler models like $\mathrm{DD}_{0}$ and improved LEC describe correctly the performance of the multipliers when there is no velocity saturation. To include this effect in LEC models, it is necessary to adjust the series resistance as a function of the frequency, doping, and multiplication factor. On the other hand, although DD model takes into account velocity saturation, it overestimates the series resistance of the diodes leading to efficiencies lower than expected, and it only works correctly when velocity saturation is the dominant effect. Hydrodynamic models are an interesting alternative to the models analyzed here. They model velocity saturation without the overestimation of the series resistance observed in DD, and, besides, their computational cost is lower than MC.

The development of Schottky multiplier above $3 \mathrm{THz}$ requires models that account for different phenomena: saturation velocity, plasma resonance, and the nonstationary performance of the electron energy and velocity. Monte Carlo and hydrodynamic models are useful tools at these frequencies.

According to Monte Carlo simulations, doublers and triplers based on GaAs Schottky diodes are expected to operate up to 6 and $4 \mathrm{THz}$, respectively with efficiency higher than $0.5 \%$. 


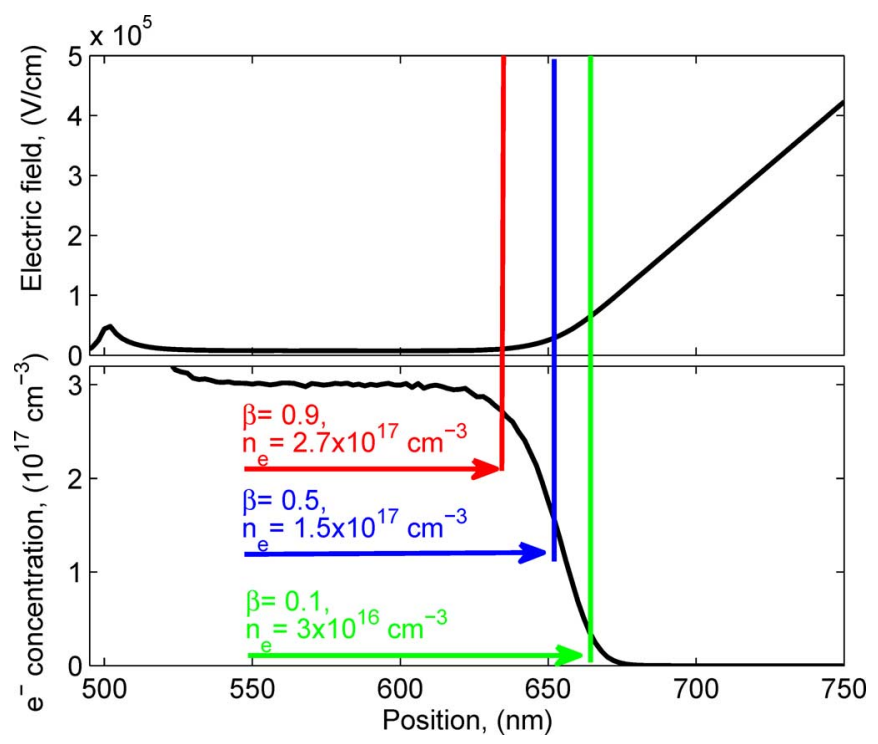

Fig. 12. Definition of the portion of the diode located between the ohmic contact (position $0 \mathrm{~nm}$ ) and the position with electron concentration $\beta N_{e}$, for the reference diode.

\section{APPENDIX}

\section{Nonlocal EfFects in the Transition BetweEn the} UNDEPLETED EPILAYER AND THE SPACE-CHARGE REGION

As a reference in this analysis, a Schottky diode with epilayer doping $3 \times 10^{17} \mathrm{~cm}^{-3}$, epilayer length $250 \mathrm{~nm}$, substrate doping $2 \times 10^{18} \mathrm{~cm}^{-3}$, and substrate length of $500 \mathrm{~nm}$ has been considered. The anode area is $1 \mu \mathrm{m}^{2}$, the ideal barrier height $0.99 \mathrm{~V}$, and the temperature $300 \mathrm{~K}$.

The electric field in the neighborhood of the Schottky contact is high and undergoes rapid variations over distances comparable to the carrier's mean free path. Therefore, the utilization of a mobility model that depends on the local electric field in the DD approximation is questionable [24], [46].

In the transition between the neutral (low-field region) and the depleted (high-field region) regions of the epilayer, the electrons move in the high-field region with a mobility higher than expected from the static velocity-field curves due to the delayed response of the electron velocity to the local electric field (energy and momentum relaxation effects ${ }^{2}$ ) [24], [72], [73]. As a consequence, the DD model overestimates the series resistance of the diode, because it uses the mobility from the static velocity-field curves.

To show the effect of this phenomenon on the impedance of the diode, an impedance $Z_{\beta}[f]$ of the portion of the diode located between the ohmic contact and the position with electron concentration $n_{e}$ equal to a determined fraction of the epilayer doping concentration $\beta N_{e}$ with $0<\beta<1$ is defined, see Fig. 12. $Z_{\beta}[f]$ has been calculated according to the following equation:

$$
Z_{\beta}[f]=\frac{V_{\beta}[f]}{I[f]}
$$

${ }^{2} \tau_{\epsilon}(\epsilon)$ and $\tau_{r n}(\epsilon)$ are the energy and momentum relaxation time respectively. $\tau_{m}(\epsilon)$ depends on the electron energy $\epsilon$. Since the adaptation of the electron energy to the variations of the electric field is determined by $\tau_{\epsilon}$ and $\tau_{\epsilon}>\tau_{m}$, the adaptation of $\tau_{m}$ to the variations of the electric field is slow.

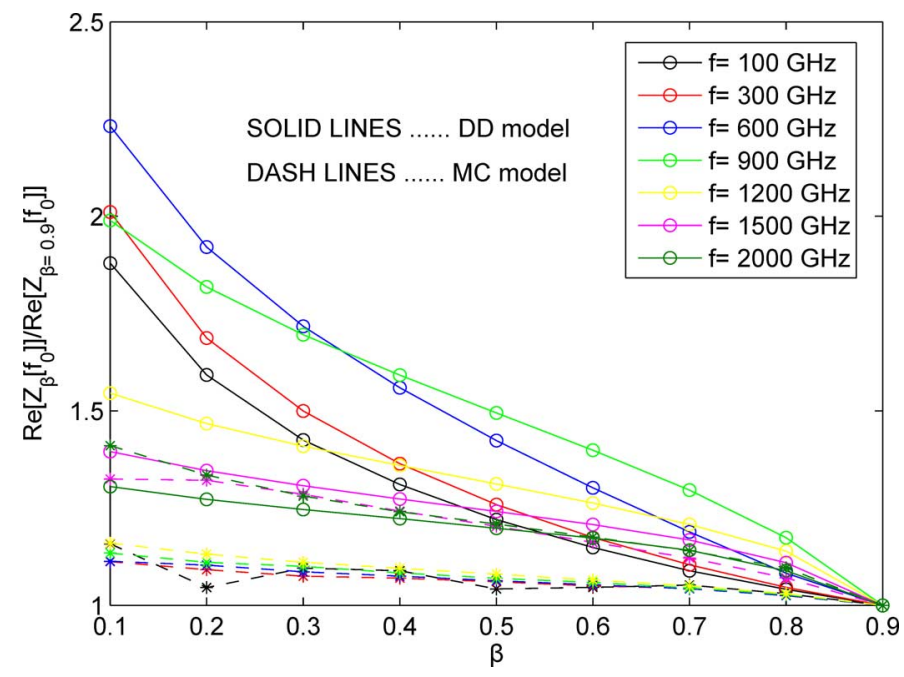

Fig. 13. Real part of the diode impedance of the reference diode simulated with the DD and MC models under sinusoidal applied signals of amplitude $1 \mathrm{~V}$, bias point $-2.0 \mathrm{~V}$ and different frequencies, for different values of $\beta$. The values presented have been normalized by the real part of $Z_{\beta}[\omega]$ with $\beta=0.9$ at each simulated frequency.

where $I[f]$ and $V_{\beta}[f]$ are the fundamental components of the Fourier series of the total current in the diode and the voltage that drops in the selected portion of the diode (calculated as $V_{\beta}(t)=-\int F(x, t) d x$, where $\mathrm{F}(\mathrm{x}, \mathrm{t})$ is the electric field as function of the position and time), respectively.

Fig. 13 presents the real part of $Z_{\beta}[f]$ normalized by the values at $\beta=0.9$ for the reference diode, simulated with the DD and MC models under sinusoidal applied signals of amplitude $1 \mathrm{~V}$, bias point $-2.0 \mathrm{~V}$ and different frequencies. It is observed that the real part of $Z_{\beta}[f]$ predicted by the DD model at $\beta=0.1$ is nearly two times the value at $\beta=0.9$ at input frequencies lower than $1200 \mathrm{GHz}$ whereas the change in the $\mathrm{MC}$ simulations is only a factor 1.1 . At higher frequencies, when the velocity saturation is reached, high fields exist also in the undepleted epilayer, so, nonlocal effects are mitigated, and the increase of the real part of $Z_{\beta}[f]$ with $\beta$ is nearly the same for both DD and MC.

These results indicate that the DD model overestimates the series resistance of the diode because of the local evaluation of the electron mobility, and when velocity saturation appears, such an error is masked; see Sections III-B and III-C. On the other hand, simulations with the $\mathrm{DD}_{0}$ model have shown the same dependence on $\beta$ as MC. Therefore, a good agreement is expected between $\mathrm{DD}_{0}$ and $\mathrm{MC}$ simulations when there is no velocity saturation.

\section{REFERENCES}

[1] P. H. Siegel, "Terahertz technology," IEEE Trans. Microw. Theory Techn., vol. 50, no. 3, pp. 910-928, Mar. 2002.

[2] T. W. Crowe, W. L. Bishop, D. W. Porterfield, J. L. Hesler, and R. M. Weikle, "Opening the terahertz window with integrated diode circuits," IEEE J. Solid-State Circuits, vol. 40, no. 10, pp. 2104-2110, Oct. 2005.

[3] P. Siegel, "THz instruments for space," IEEE Trans. Antennas Propag., vol. 55, no. 11, pp. 2957-2965, Nov. 2007.

[4] A. Maestrini, B. Thomas, H. Wang, C. Jung, J. Treuttel, Y. Jin, G. Chattopadhyay, I. Mehdi, and G. Beaudin, "Schottky diode-based terahertz frequency multipliers and mixers," C. R. Phys., vol. 11, no. 7-8, pp. 480-495, Aug. 2010. 
[5] G. Chattopadhyay, "Technology, capabilities, and performance of low power terahertz sources," IEEE Trans. THz Sci. Technol., vol. 1, no. 1, pp. 33-53, Sep. 2011

[6] J. Ward, F. Maiwald, G. Chattopadhyay, E. Schlecht, A. Maestrini, J. Gill, and I. Mehdi, "1400-1900 GHz local oscillators for the Herschel space observatory," in Proc. 14th Int. Symp. Space THz Tech., Tucson, AZ, USA, Apr. 2003, p. 94.

[7] A. Maestrini, J. Ward, J. Gill, H. Javadi, E. Schlecht, C. TriponCanseliet, G. Chattopadhyay, and I. Mehdi, "A 540-640 GHz high efficiency four-anode frequency tripler," IEEE Trans. Microw. Theory Techn., vol. 53, no. 9, pp. 2835-2843, Sep. 2005.

[8] A. Maestrini, J. Ward, H. Javadi, C. Tripon-Canseliet, J. Gill, G. Chattopadhyay, E. Schlecht, and I. Mehdi, "Local oscillator chain for 1.55 to $1.75 \mathrm{THz}$ with $100-\mu \mathrm{W}$ peak power," IEEE Microw. Wireless Compon. Lett., vol. 15, no. 12, pp. 871-873, Dec. 2005.

[9] T. de Graauw et al., "The Herschel-heterodyne instrument for the farinfrared (HIFI)," Astron. Astrophys., vol. 518, Jul. 2010.

[10] A. Maestrini, J. Ward, J. Gill, C. Lee, B. Thomas, R. Lin, G. Chattopadhyay, and I. Mehdi, "A frequency-multiplied source with more than 1 $\mathrm{mW}$ of power across the $840-900-\mathrm{GHz}$ band," IEEE Trans. Microw. Theory Techn., vol. 58, no. 7, pp. 1925-1932, Jul. 2010.

[11] T. Crowe, J. Hesler, S. Retzloff, C. Pouzou, and G. Schoenthal, "Solidstate LO sources for greater than 2 THz," in Proc. 22nd Int. Symp. Space THz Tech., Tucson, AZ, USA, Apr. 2011, pp. 209-212.

[12] A. Maestrini, I. Mehdi, J. Siles, J. Ward, R. Lin, B. Thomas, C. Lee, J. Gill, G. Chattopadhyay, E. Schlecht, J. Pearson, and P. Siegel, "Design and characterization of a room temperature all-solid-state electronic source tunable from 2.48 to $2.75 \mathrm{THz}$," IEEE Trans. THz Sci. Technol., vol. 2, no. 2, pp. 177-185, Mar. 2012.

[13] P. H. Siegel, R. P. Smith, M. C. Graidis, and S. C. Martin, " $2.5-\mathrm{THz}$ GaAs monolithic membrane-diode mixer," IEEE Trans. Microw. Theory Techn., vol. 47, no. 5, pp. 596-604, May 1999.

[14] B. Thomas, A. Maestrini, D. Matheson, I. Mehdi, and P. de Maagt, "Design of an $874 \mathrm{GHz}$ biasable sub-harmonic mixer based on MMIC membrane planar Schottky diodes," in Proc. 33rd Int. Conf. Infrared, Millimeter, and Terahertz Waves, Sep. 2008, pp. 1-2.

[15] B. Thomas, A. Maestrini, J. Gill, C. Lee, R. Lin, I. Mehdi, and P. de Maagt, "A broadband $835-900-\mathrm{GHz}$ fundamental balanced mixer based on monolithic GaAs membrane Schottky diodes," IEEE Trans. Microw. Theory Techn., vol. 58, no. 7, pp. 1917-1924, Jul. 2010.

[16] B. Thomas, J. Gill, A. Maestrini, C. Lee, R. Lin, S. Sin, A. Peralta, and I. Mehdi, "An integrated 520-600 GHz sub-harmonic mixer and tripler combination based on GaAs MMIC membrane planar Schottky diodes," in Proc. 35th Int. Conf. Infrared, Millimeter, and Terahertz Waves, Sep. 2010, pp. 1-2.

[17] J. Hesler, H. Xu, T. Reck, and T. Crowe, "Development and testing of a 2.5 THz Schottky mixer," in Proc. 36th Int. Conf. Infrared, Millimeter and Terahertz Waves, Houston, TX, USA, Oct. 2011, pp. 1-2.

[18] P. Penfield and R. Rafuse, Varactor Applications. Cambridge, MA USA: MIT, 1962.

[19] K. Champlin and G. Eisenstein, "Cutoff frequency of submillimeter Schottky-barrier diodes," IEEE Trans. Microw. Theory Techn., vol. MTT-26, no. 1, pp. 31-34, Jan. 1978.

[20] T. W. Crowe, "GaAs Schottky barrier mixer diodes for the frequency range 1-10 THz,” Int. J. Infrared Millimeter Waves, vol. 10, no. 7, pp. 765-777, Jul. 1989.

[21] N. R. Erickson, "Diode frequency multipliers for THz local oscillator applications,” in Proc. SPIE, Kona, HI, USA, Jul. 1998, vol. 3357, pp. 75-84.

[22] E. Schlecht, F. Maiwald, G. Chattopadhyay, S. Martin, and I. Mehdi, "Design considerations for heavily-doped cryogenic Schottky diode varactor multipliers," in Proc. 12th Int. Symp. Space Terahertz Tech., San Diego, CA, USA, Feb. 2001, p. 485.

[23] S. Selberherr, Analysis and Simulation of Semiconductor Devices. New York, NY, USA: Springer-Verlag, 1984.

[24] M. Lundstrom, Fundamentals of Carrier Transport, 2nd ed. Cambridge, U.K.: Cambridge Univ., 2000.

[25] J. Grajal, V. Krozer, E. Gonzalez, F. Maldonado, and J. Gismero, "Modeling and design aspects of millimeter-wave and submillimeter-wave Schottky diode varactor frequency multipliers,' IEEE Trans. Microw. Theory Techn., vol. 48, no. 4, pp. 700-711, Apr. 2000 .

[26] K. Blotekjaer, "Transport equations for electrons in two-valley semiconductors," IEEE Trans. Electron Devices, vol. ED-17, no. 1, pp. 38-47, Jan. 1970.

[27] H. Hjelmgren and T. W. Tang, "Thermionic emission in a hydrodynamic model for heterojunction structures," Solid-State Electron., vol. 37, no. 9, pp. 1649-1657, 1994.
[28] C. Lee, B. Gelmont, D. Woolard, and C. Fazi, "A modified harmonicbalance analysis of Schottky diode multipliers based upon a hydrodynamic transport model," in Proc. 10th Int. Symp. Space Terahertz Tech., Charlottesville, VA, USA, Mar. 1999, p. 312.

[29] C. Jacoboni and P. Lugli, The Monte Carlo Method for Semiconductor Device Simulation. New York, NY, USA: Springer-Verlag, 1989.

[30] T. González, J. E. Velázquez, P. M. Gutiérrez, and D. Pardo, "Fivevalley model for the study of electron transport properties at very high electric fields in GaAs," Semicond. Sci. Technol., vol. 6, no. 9, p. 862, Sep. 1991.

[31] U. V. Bhapkar, "Monte Carlo simulation of gallium arsenide Schottky diodes for terahertz frequencies," Ph.D. dissertation, Univ. of Virginia, Charlottesville, VA, USA, 1995.

[32] J. East, "Monte Carlo simulation of Schottky barrier mixers and varactors," in Proc. 6th Int. Symp. Space Terahertz Tech., Pasadena, CA, USA, Mar. 1995, pp. 442-457.

[33] R. Lipsey, S. Jones, J. Jones, T. Crowe, L. Horvath, U. Bhapkar, and R. Mattauch, "Monte Carlo harmonic-balance and drift-diffusion harmonic-balance analyses of 100-600 GHz Schottky barrier varactor frequency multipliers," IEEE Trans. Electron Devices, vol. 44, no. 11, pp. 1843-1850, Nov. 1997.

[34] E. T. Schlecht, G. Chattopadhyay, A. Maestrini, D. Pukala, J. Gill, and I. Mehdi, "Harmonic balance optimization of terahertz Schottky diode multipliers using an advanced device mode," in Proc. 13th Int. Symp. Space Terahertz Tech., Cambridge, MA, USA, Mar. 2002, pp. 187-196.

[35] A. Aishima and Y. Fukushima, "Numerical study of an n-gallium arsenide diode distributed oscillator," J. Appl. Phys., vol. 56, no. 4, pp. 1086-1092, 1984.

[36] E. Kolberg, T. Tolmunen, M. Frerking, and J. East, "Current saturation in submillimeter-wave varactors," IEEE Trans. Microw. Theory Techn, vol. 40, no. 5, pp. 831-838, May 1992.

[37] J. R. Jones, S. H. Jones, and G. B. Tait, "Self consistent physics-based numerical device and harmonic balance circuit analysis of heterostructure barrier and Schottky barrier varactors including thermal effects,' in Proc. 6th Int. Symp. Space Terahertz Tech., Pasadena, CA, USA, Mar. 1995, p. 423.

[38] W. L. Schroeder and I. Wolff, "Monte-Carlo study of high-frequency, large-signal transport parameters for physics based device simulation," IEEE Trans. Electron Devices, vol. 42, no. 5, pp. 819-827, May 1995.

[39] R. Lipsey and S. Jones, "Accurate design equations for 50-600 GHz GaAs Schottky diode varactor frequency doublers," IEEE Trans. Electron Devices, vol. 45, no. 9, pp. 1876-1882, Sep. 1998.

[40] E. Schlecht, G. Chattopadhyay, A. Maestrini, D. Pukala, J. Gill, S. Martin, F. Maiwald, and I. Mehdi, "A high-power wideband cryogenic $200 \mathrm{GHz}$ Schottky substrateless multiplier: Modeling, design and results," in Proc. 9th. Int. Conf. Terahertz Electron., Charlottesville, VA, USA, 2001, pp. 485-494.

[41] A. Kerr, "A technique for determining the local oscillator waveforms in a microwave mixer (short papers)," IEEE Trans. Microw. Theory Techn., vol. MTT-23, no. 10, pp. 828-831, Oct. 1975.

[42] E. H. Rhoderick and R. H. Williams, Metal-Semiconductor Contacts, 2nd ed. Oxford, U.K.: Clarendon, 1988.

[43] C. Burckhardt, "Analysis of varactor frequency multipliers for arbitrary capacitance variation and drive level," Bell Syst. Tech. J., vol. 44, no. 4, pp. 675-692, Apr. 1965.

[44] T. Newman and N. Erickson, "A planar varactor array multiplier chain to $300 \mathrm{GHz}$," in IEEE MTT-S Int. Microw. Symp. Dig., Anaheim, CA, USA, Jun. 1999, vol. 1, pp. 135-138.

[45] A. Maestrini, J. Ward, J. Gill, G. Chattopadhyay, F. Maiwald, K. Ellis, H. Javadi, and I. Mehdi, "A planar-diode frequency tripler at $1.9 \mathrm{THz}$," in IEEE MTT-S Int. Microw. Symp. Dig., Philadelphia, PA, USA, Jun. 2003, pp. 747-750.

[46] P. Sandborn, A. Rao, and P. Blakey, "An assessment of approximate nonstationary charge transport models used for GaAs device modeling," IEEE Trans. Electron Devices, vol. 36, no. 7, pp. 1244-1253, Jul. 1989.

[47] M. V. Fischetti and S. E. Laux, "Monte Carlo analysis of electron transport in small semiconductor devices including band-structure and space-charge effects," Phys. Rev. B, vol. 38, no. 14, pp. 9721-9745, Nov. 1988.

[48] W. Kelly and G. Wrixon, "Conversion losses in Schottky-barrier diode mixers in the submillimeter region," IEEE Trans. Microw. Theory Techn., vol. MTT-27, no. 7, pp. 665-672, Jul. 1979.

[49] F. Maiwald, E. Schlecht, A. Maestrini, G. Chattopadhyay, J. C. Pearson, D. Pukala, and I. Mehdi, "THz frequency multiplier chains based on planar Schottky diodes," in Proc. SPIE, Feb. 2003, vol. 4855, pp. $447-458$. 
[50] G. Chattopadhyay, E. Schlecht, J. S. Ward, J. J. Gill, H. H. S. Javadi, F. Maiwald, and I. Mehdi, "An all-solid-state broad-band frequency multiplier chain at $1500 \mathrm{GHz}$," IEEE Trans. Microw. Theory Techn., vol. 52, no. 5, pp. 1538-1547, May 2004.

[51] G. Chattopadhyay, E. Schlecht, J. Gill, S. Martin, A. Maestrini, D. Pukala, F. Maiwald, and I. Mehdi, "A broadband $800 \mathrm{GHz}$ Schottky balanced doubler," IEEE Microw. Wireless Compon. Lett., vol. 12, no. 4, pp. 117-118, Apr. 2002

[52] J. V. Siles and J. Grajal, "Physics-based design and optimization of Schottky diode frequency multipliers for terahertz applications," IEEE Trans. Microw. Theory Techn., vol. 58, no. 7, pp. 1933-1942, Jul. 2010.

[53] F. Maiwald, E. Schlecht, G. Chattopadhyay, A. Maestrini, and J. Gill, "Planar GaAs Schottky Diode Frequency Multiplier Chains up to 3 THz," Inst. Microw. Eng., Darmstadt, Germany, 2002 [Online]. Available: http://hdl.handle.net/2014/8709

[54] J. L. Hesler and B. L. Gelmont, "A discussion of power coupling bandwidth limitations of planar Schottky diodes at submillimeter wavelengths," in Proc. 9th Int. Symp. Space Terahertz Tech., Pasadena, CA, USA, Mar. 1998, p. 173.

[55] M. Faber, J. Archer, and R. Mattauch, "A high efficiency frequency doubler for $100 \mathrm{GHz}$," in IEEE MTT-S Int. Microw. Symp. Dig., 1985, pp. 363-365.

[56] A. Y. Tang, E. Schlecht, R. Lin, G. Chattopadhyay, C. Lee, J. Gill, I. Mehdi, and J. Stake, "Electro-thermal model for multi-anode Schottky diode multipliers," IEEE Trans. THz Sci. Technol., vol. 2, no. 3, pp. 290-298, May 2012.

[57] A. Maestrini, J. Ward, C. Tripon-Canseliet, J. Gill, C. Lee, H. Javadi, G. Chattopadhyay, and I. Mehdi, "In-phase power-combined frequency tripler at $300 \mathrm{GHz}$," IEEE Microw. Wireless Compon. Lett., vol. 18, no. 3, pp. 218-220, Mar. 2008.

[58] J. Ward, E. Schlecht, G. Chattopadhyay, A. Maestrini, J. Gill, F. Maiwald, H. Javadi, and I. Mehdi, "Capability of THz sources based on Schottky diode frequency multiplier chains," in IEEE MTT-S Int. Microw. Symp. Dig., Jun. 2004, pp. 1587-1590.

[59] N. Erickson, G. Narayanan, R. Grosslein, A. G. Chattopadhyay, A. Maestrini, E. Schlecht, I. Mehdi, and S. Martin, " $1500 \mathrm{GHz}$ tunable source using cascaded planar frequency doublers," in Proc. 13th Int. Symp. Space Terahertz Tech., Cambridge, MA, USA, Mar. 2002, p. 177.

[60] J. Bruston, A. Maestrini, D. Pukala, S. Martin, B. Nakamura, and I. Mehdi, "A 1.2 THz planar tripler using GaAs membrane based chips," in Proc. 12th Int. Symp. Space Terahertz Tech., San Diego, CA, USA, Dec. 2001, p. 310.

[61] A. Maestrini, J. Bruston, D. Pukala, S. Martin, and I. Mehdi, "Performance of a $1.2 \mathrm{THz}$ frequency tripler using a GaAs frameless membrane monolithic circuit," in IEEE MTT-S Int. Microw. Symp. Dig., Phoenix, AZ, USA, May 2001, pp. 1657-1660.

[62] N. R. Erickson, G. Narayanan, R. M. Grosslein, S. Martin, P. Smith, I. Mehdi, M. Coulomb, and G. Demartinez, "Monolithic THz frequency multipliers," in Proc. 12th Int. Symp. Space Terahertz Tech., San Diego, CA, USA, Feb. 2001, p. 297.

[63] F. Maiwald, S. Martin, J. Bruston, A. Maestrini, T. Crawford, and P. Siegel, "2.7 THz waveguide tripler using monolithic membrane diodes," in IEEE MTT-S Int. Microw. Symp. Dig., Phoenix, AZ, USA, May 2001, pp. 1637-1640.

[64] F. Maiwald, S. Martin, J. Bruston, A. Maestrini, T. Crawford, and P. H. Siegel, "Design and performance of a 2.7 THz waveguide tripler," in Proc. 12th Int. Symp. Space Terahertz Tech., San Diego, CA, USA, Feb. 2001, p. 320.

[65] A. Maestrini, J. Ward, J. Gill, H. Javadi, E. Schlecht, G. Chattopadhyay, F. Maiwald, N. Erickson, and I. Mehdi, "A 1.7-1.9 THz local oscillator source," IEEE Microw. Wireless Compon. Lett., vol. 14, no. 6, pp. 253-255, Jun. 2004.

[66] T. W. Crowe, J. L. Hesler, C. Pouzou, W. L. Bishop, and G. S. Schoenthal, "Development and characterization of a 1.9 THz LO source," in Proc. 21th Int. Symp. Space Terahertz Tech., Oxford, U.K., Mar. 2010, p. 472 .

[67] J. C. Pearson, B. J. Drouin, A. Maestrini, I. Mehdi, J. Ward, R. H. Lin, S. Yu, J. J. Gill, B. Thomas, C. Lee, G. Chattopadhyay, E. Schlecht, F. W. Maiwald, P. F. Goldsmith, and P. Siegel, "Demonstration of a room temperature $2.48-2.75 \mathrm{THz}$ coherent spectroscopy source," Rev. Sci. Instrum., vol. 82, no. 9, Sep. 2011, Art. ID 093105.

[68] A. Maestrini, I. Mehdi, R. Lin, J. V. Siles, C. Lee, J. Gill, G. Chattopadhyay, E. Schlecht, B. Thomas, and J. Ward, "A 2.5-2.7 THz room temperature electronic source," in Proc. 22nd Int. Symp. Space Terahertz Tech., Tucson, AZ, USA, Apr. 2011.

[69] A. Betz and R. Boreiko, "A practical Schottky mixer for $5 \mathrm{THz}$ (Part II)," in Proc. 7th Int. Symp. Space Terahertz Tech., Charlottesville, VA, USA, Mar. 1996, p. 503.
[70] K. Nakayama, S. Okajima, K. Kawahata, K. Tanaka, and T. Akiyama, "Application of a GaAs Schottky barrier diode mixer to beat signal detection of the 5-6 THz band," in Proc. 36th Int. Conf. Infrared, Millimeter and Terahertz Waves, Houston, TX, USA, Oct. 2011, pp. $1-2$.

[71] K. S. Champlin, D. B. Armstrong, and P. D. Gunderson, "Charge carrier inertia in semiconductors," Proc. IEEE, vol. 52, no. 6, pp. 677-685, Jun. 1964.

[72] R. Grondin, P. Blakey, and J. East, "Effects of transient carrier transport in millimeter-wave GaAs diodes," IEEE Trans. Electron Devices, vol. ED-31, no. 1, pp. 21-28, Jan. 1984.

[73] R. P. Joshi and D. K. Ferry, "Calculations of the temperature and field dependent electronic mobility in $\beta$-SiC," Solid-State Electron., vol. 38, no. 11, pp. 1911-1916, Nov. 1995.

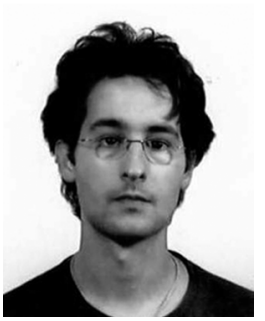

Diego Pardo was born in Salamanca, Spain, in 1984. He received the degree in theoretical physics from the University of Salamanca, Salamanca, Spain, in 2008. $\mathrm{He}$ is currently working toward the Ph.D. degree at the Signal, System, and Radiocommunications Department, Technical University of Madrid, Madrid, Spain.

Since 2009, he has been with the Signals, System, and Radiocommunications Department, Technical University of Madrid. His research activities are in the area of semiconductor device modeling, including physic-based noise analysis.

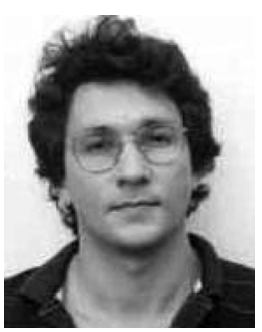

Jesús Grajal was born in Toral de los Guzmanes (León), Spain, in 1967. He received the Ingeniero de Telecomunicación degree and Ph.D. degree from the Technical University of Madrid, Madrid, Spain, in 1992 and 1998, respectively.

In 1993, he joined the Signal, System, and Radiocommunications Department, Technical University of Madrid, Madrid, Spain, where he has been an Associate Professor since 1998. His research activities are in the area of semiconductor device modeling and high-frequency circuit and system design.

Dr. Grajal was a corecipient of the 2013 EuCAP Best Antenna Design Paper Award.

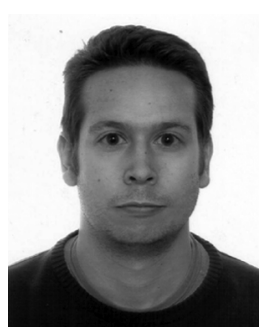

Carlos G. Pérez-Moreno was born in Madrid, Spain, in 1985. He received the Ingeniero de Telecomunicación degree from the Technical University of Madrid, Madrid, Spain, in 2011, where he is currently working toward the Ph.D. degree at the Signal, System, and Radiocommunications Department.

Since 2008, he has been with the Signal, System, and Radiocommunications Department at Technical University of Madrid. His research activities are in the area of semiconductor device modeling.

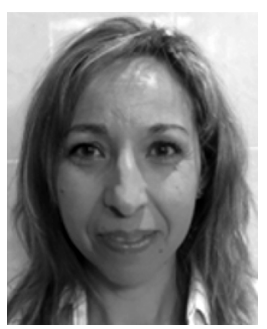

Susana Pérez was born in Salamanca, Spain, in 1970. She received the M.S. and Ph.D. degrees from the University of Salamanca, Salamanca, Spain, in 1993 and 1999, respectively, both in physics.

Since 1994, she has been with the Applied Physics Department, University of Salamanca, Salamanca, Spain, where she became an Associate Professor in 2009. She was a Visiting Researcher with the LCR of Thomson-CSF (Thales), Orsay, France, and with the IRCOM (Xlim), Limoges, France. Her current research interests are in the development of terahertz devices and the field of numerical simulation of electronic transport and noise in submicrometer semiconductor devices. 